\title{
Article
}

\section{Perio-endo lesions: a guide to diagnosis and clinical management}

Sonde, Nargis and Edwards, Malcolm Robert

Available at http://clok.uclan.ac.uk/34821/

Sonde, Nargis ORCID: 0000-0002-0636-3211 and Edwards, Malcolm Robert (2020) Perio-endo lesions: a guide to diagnosis and clinical management.

Primary Dental Journal, 9 (4). pp. 45-51. ISSN 2050-1684

It is advisable to refer to the publisher's version if you intend to cite from the work. http://dx.doi.org/10.1177/2050168420963305

For more information about UCLan's research in this area go to

http://www.uclan.ac.uk/researchgroups/ and search for <name of research Group>.

For information about Research generally at UCLan please go to

http://www.uclan.ac.uk/research/

All outputs in CLoK are protected by Intellectual Property Rights law, including Copyright law. Copyright, IPR and Moral Rights for the works on this site are retained by the individual authors and/or other copyright owners. Terms and conditions for use of this material are defined in the policies page.

\section{CLoK}

Central Lancashire online Knowledge www.clok.uclan.ac.uk

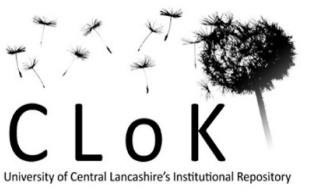




\title{
Perio-Endo Lesions - A Guide to their Diagnoses \& Clinical Management
}

\section{Learning Objectives}

- To understand the role of periodontal considerations when treatment planning for endodontic lesions.

- To gain an understanding about lesions with a periodontal and endodontic component and how to diagnose and manage them.

Keywords: Periodontology, Endodontology, Combined Lesion, Perio-Endo Lesion

\begin{abstract}
Dentists are likely to encounter lesions that have both periodontal and endodontic aetiological components; the so called 'perio-endo lesions'. A thorough examination with appropriate investigations remains pivotal to diagnosing a 'perio-endo lesion'. Correct diagnosis of such lesions is therefore important as it enables the most suitable clinical management to be treatment planned. It is still recommended, that for the treatment of 'perio-endo lesions', initial endodontic therapy is completed.
\end{abstract}

\section{Introduction}

The interface between the periodontium and the tooth has long been an area of interest due to its complex anatomy and physiology. When inflammation presents on a tooth which is associated with both pulpal pathology and the periodontal tissues, it is classed as a perio-endo lesion. With an increasing number of clinicians training in mono-specialties, a greater understanding of multidisciplinary collaboration is needed and should be encouraged between specialists and primary care practitioners. The perio-endo interface provides this opportunity for teams to work together more closely in order to achieve good clinical results for their patient. Cases of perio-endo lesions, whether primary, secondary or the rarely seen true combined lesion, can provide a level of complexity to challenge the willing clinician and team.

\section{Channels of Communication}

There are numerous routes for communication between the pulp and the periodontal tissue. Each of these, either alone or in combination, has the potential to affect the vitality of the pulp and the health of the periodontal tissues. A few of these channels are demonstrated in Figure 1. 


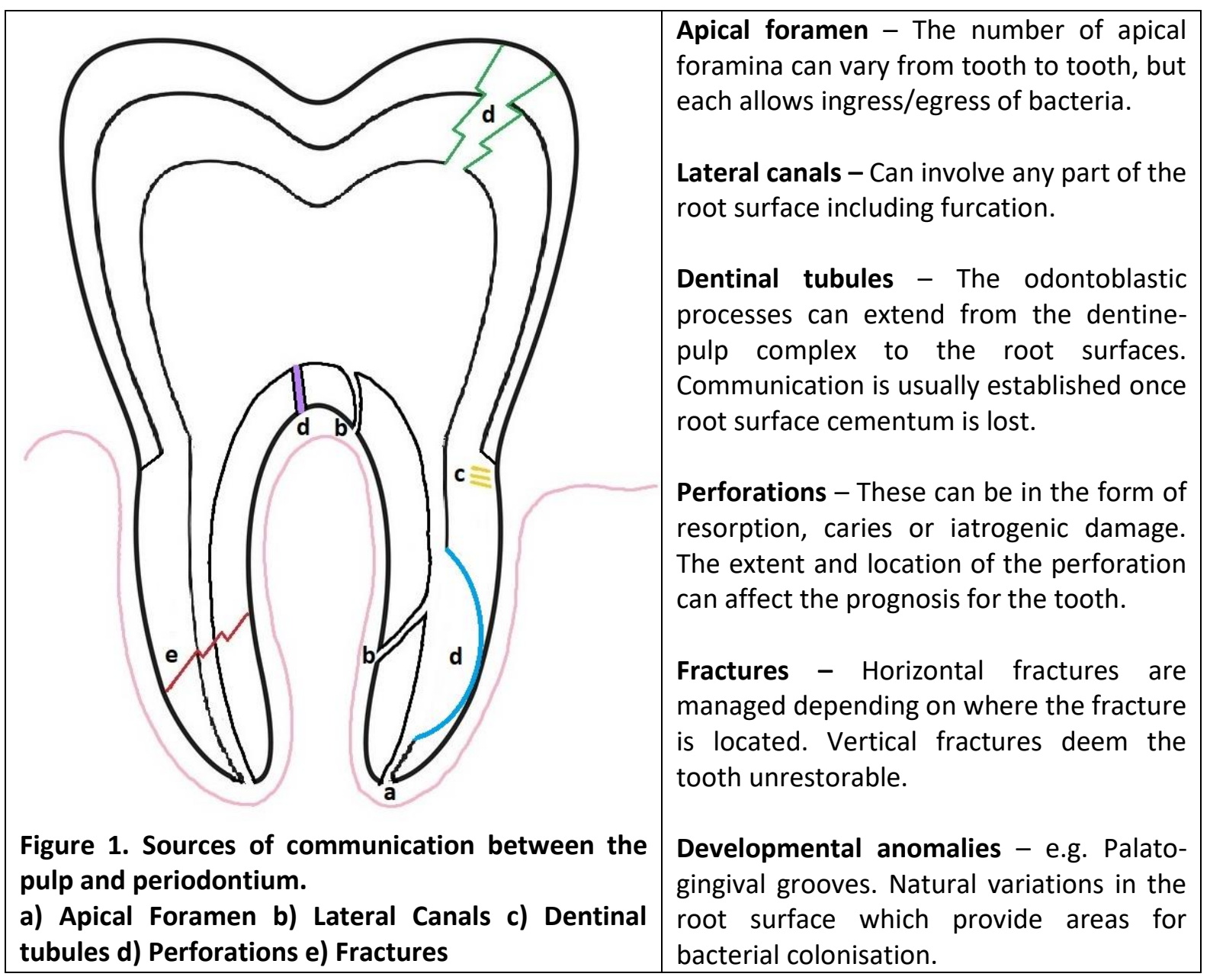

\section{Classification}

Perio-endo lesions can be classified as five distinct types of lesions (1):

1. Primary Endodontic Lesion - This is where the problem is purely endodontic in nature, but the lesion happens to be draining through the gingival tissue. It is not unusual for drainage to present through the gingival crevice or the area of furcation. Its origin can be traced back to the source of infection by taking a periapical with a gutta percha (GP) point inserted from the drainage site (see Figure 2).

2. Primary Endodontic Lesion with Secondary Periodontal involvement - This occurs when a primary endodontic infection persists, destroys the surrounding tissue and infiltrates into the inter-radicular space. This leads to persistent drainage through the gingival tissues, creating a site where plaque and calculus can accumulate leading to periodontal disease.

3. Primary Periodontal Lesion - This is the classic appearance of periodontal disease where pocket formation occurs due to plaque or calculus accumulation leading to loss of attachment. Patients with periodontal disease are likely to have multiple sites of pocketing, provided a local factor, such as an overhanging restoration or occlusal trauma is absent.

4. Primary Periodontal Lesion with Secondary Endodontic Involvement - This happens when periodontal disease progresses down the root surface and leads to an area of communication with the pulp. The most obvious way this may occur is when periodontal disease progresses to the apical foramen but may also occur if other channels of communication with the pulp become exposed. Its features are like a primary endodontic lesion with secondary periodontal involvement and is differentiated based on which disease process presents first. 
5. True Combined Lesion - This diagnosis can be given when the two separate processes have started independent of each other but happen to coalesce. The periodontal lesion exists and progresses, whilst during the same period the tooth devitalises, and the apical lesion progresses. These two fronts spread across the root surface and meet to form the combined lesion.

6. The Concomitant Pulpal-Periodontal Lesion (2) - Although not part of the original classification by Smith et al. (1972), this term has been suggested to describe the presentation of both pulpal and periodontal conditions on the same tooth which appear to exist independent of each other.

A summary of the clinical features of these lesions have been presented in Table 1.

\begin{tabular}{|c|c|c|c|c|}
\hline Diagnosis & Origin & $\begin{array}{l}\text { Radiographic } \\
\text { Appearance }\end{array}$ & $\begin{array}{c}\text { Restoration Status } \\
\text { of tooth }\end{array}$ & Clinical Indicators \\
\hline $\begin{array}{l}\text { Primary } \\
\text { Endodontic Lesion }\end{array}$ & Pulp & $\begin{array}{l}\text { A localised apical } \\
\text { radiolucency. } \\
\text { May appear on the } \\
\text { lateral or furcation } \\
\text { areas of the root } \\
\text { surface where } \\
\text { lateral canals are } \\
\text { present. }\end{array}$ & $\begin{array}{l}\text { Caries } \\
\text { Deep restorations } \\
\text { Crowned teeth } \\
\text { History of trauma }\end{array}$ & $\begin{array}{l}\text { Tender to } \\
\text { percussion (TTP) } \\
\text { Negative to vitality } \\
\text { testing. }\end{array}$ \\
\hline $\begin{array}{l}\text { Primary } \\
\text { Endodontic Lesion } \\
\text { with Secondary } \\
\text { Periodontal } \\
\text { Involvement }\end{array}$ & Pulp & $\begin{array}{l}\text { As per a primary } \\
\text { endodontic lesion } \\
\text { but with evidence } \\
\text { of interradicular/ } \\
\text { interdental bone } \\
\text { loss - with a } \\
\text { horizontal or } \\
\text { vertical pattern. }\end{array}$ & $\begin{array}{l}\text { Caries } \\
\text { Deep restorations } \\
\text { Crowned teeth } \\
\text { History of trauma }\end{array}$ & $\begin{array}{l}\text { TTP } \\
\text { Negative to vitality } \\
\text { testing. } \\
\text { Narrow pocket } \\
\text { with or without } \\
\text { suppuration. } \\
\text { Mobility }\end{array}$ \\
\hline $\begin{array}{l}\text { Primary } \\
\text { Periodontal Lesion }\end{array}$ & Periodontium & $\begin{array}{l}\text { Interdental/interra } \\
\text { dicular bone loss } \\
\text { with a horizontal or } \\
\text { vertical pattern. } \\
\text { Areas of } \\
\text { radiolucency along } \\
\text { the lateral aspects } \\
\text { of the root surface } \\
\text { but may be visible } \\
\text { in the area of } \\
\text { furcation }\end{array}$ & $\begin{array}{l}\text { Caries may or may } \\
\text { not be present. } \\
\text { Tooth may be } \\
\text { unrestored or have } \\
\text { a small restoration. }\end{array}$ & $\begin{array}{l}\text { Positive to vitality } \\
\text { testing. } \\
\text { Wider pocket with } \\
\text { or without } \\
\text { suppuration } \\
\text { Pockets more } \\
\text { generalised } \\
\text { Mobility }\end{array}$ \\
\hline $\begin{array}{l}\text { Primary } \\
\text { Periodontal Lesion } \\
\text { with Secondary } \\
\text { Endodontic } \\
\text { Involvement }\end{array}$ & Periodontium & $\begin{array}{l}\text { Same as for a } \\
\text { primary } \\
\text { periodontal lesion } \\
\text { but the radiolucent } \\
\text { area usually } \\
\text { extends to the } \\
\text { apical region. }\end{array}$ & $\begin{array}{l}\text { Caries may or may } \\
\text { not be present. }\end{array}$ & $\begin{array}{l}\text { Negative to vitality } \\
\text { testing. } \\
\text { Wider pocket with } \\
\text { or without } \\
\text { suppuration } \\
\text { Pockets more } \\
\text { generalised } \\
\text { Mobility }\end{array}$ \\
\hline Combined Lesion & $\begin{array}{l}\text { Pulp and } \\
\text { Periodontium }\end{array}$ & $\begin{array}{l}\text { A combination of a } \\
\text { primary }\end{array}$ & $\begin{array}{l}\text { Caries may or may } \\
\text { not be present. }\end{array}$ & Well localised pain. \\
\hline
\end{tabular}




\begin{tabular}{|c|c|c|c|c|}
\hline & & $\begin{array}{l}\text { endodontic and } \\
\text { primary } \\
\text { periodontal lesion } \\
\text { where areas of } \\
\text { radiolucency seem } \\
\text { to originate from } \\
\text { the } \\
\text { interdental/inter- } \\
\text { radicular space and } \\
\text { the apical area. }\end{array}$ & $\begin{array}{l}\text { Deep restorations } \\
\text { Crowned teeth } \\
\text { History of trauma }\end{array}$ & $\begin{array}{l}\text { Negative to vitality } \\
\text { testing. } \\
\text { TTP } \\
\text { Wider pocket with } \\
\text { or without } \\
\text { suppuration } \\
\text { Mobility }\end{array}$ \\
\hline $\begin{array}{l}\text { Concomitant } \\
\text { Pulpal-Periodontal } \\
\text { Lesion }\end{array}$ & $\begin{array}{l}\text { Pulp and } \\
\text { Periodontium }\end{array}$ & $\begin{array}{l}\text { Appearance of a } \\
\text { primary } \\
\text { endodontic and } \\
\text { primary } \\
\text { periodontal lesion } \\
\text { where areas of } \\
\text { radiolucency do } \\
\text { not coalesce and } \\
\text { appear separate } \\
\text { from each other. }\end{array}$ & $\begin{array}{l}\text { Caries may or may } \\
\text { not be present. } \\
\text { Deep restorations } \\
\text { Crowned teeth } \\
\text { History of trauma }\end{array}$ & $\begin{array}{l}\text { Well localised pain. } \\
\text { Negative to vitality } \\
\text { testing. } \\
\text { TTP } \\
\text { Wider pocket with } \\
\text { or without } \\
\text { suppuration } \\
\text { Mobility }\end{array}$ \\
\hline
\end{tabular}

Table 1. A summary of clinical and radiographic features

\section{Differential Diagnosis}

It can be quite exciting to diagnose the rare perio-endo lesion, or more convenient to assign a common diagnosis which solely requires root canal treatment, non-surgical periodontal treatment or extraction. Accurate diagnosis is essential to ensure correct treatment is undertaken in order to alleviate symptoms the patient is experiencing. The wrong diagnosis, even by the most considerate clinician can adversely affect the clinician-patient relationship, may discourage the patient from seeking help in the future, may lead to a complaint or prove detrimental to the patient's health in the future. At times a diagnosis is achieved by a process of elimination which can help the clinician maintain an open mind in the investigative process. Some of the following conditions can present with similar characteristics or in the same location as a perio-endo lesion:

- Root fractures - Due to the presence of a communication between the pulp and periodontal tissues, the cleavage planes of a fracture become an ideal location for bacteria to colonise. Fractures which are not evident clinically should be investigated under magnification using transillumination and/or methylene blue dye. It should be noted that fractures can be difficult to diagnose and at times may only become evident after accessing the pulp chamber or extracting the tooth.

- Periodontal abscess - This is an acute infection of a periodontal pocket which can present with a localised swelling. It is differentiated from a perio-endo lesion as there is no endodontic lesion and the tooth remains vital (3).

- Lateral periodontal cysts - These are rare developmental odontogenic cysts suspected to originate from the rest of Malassez. They are usually incidental findings radiographically appearing as well demarcated lesions located on the lateral aspect of the root surface. The tooth itself is usually vital and can often be retained following enucleation of the associated cyst (4).

- Other Conditions - Occasionally lesions occur which do not seem to present as either periodontal or endodontic conditions and do not respond to treatment. These will need to be 
investigated further most likely with cone beam computed tomography (CBCT) or a biopsy to exclude the possibility of systemic diseases. Though very rare, conditions such as scleroderma, metastatic carcinoma and osteosarcomas can have the radiographic appearance of periodontal or endodontic disease and should arise suspicion where a more common cause cannot be determined (5).

\section{Diagnosis}

\section{- History}

A good patient history remains invaluable to the clinician when forming a diagnosis. The patient's description of their symptoms can help to narrow the area of investigation and in some cases, they may even know what is wrong due to a previous experience or an existing diagnosis. The common features which patients will complain of is pain, swelling, 'wobbly' teeth and maybe even a bad taste. Pain in the case of the combined lesion is usually well localised and in the acute stages, quite severe. The patient and/or dentist may already be aware of active periodontal disease or an endodontic lesion from previous visits, investigations or existing radiographs.

\section{- Clinical Examination}

Whilst assessing the patient there may be clinical evidence of disease. Caries (primary or secondary) may be evident on visual examination and require further investigation. The tooth itself may present with signs of periodontal or endodontic disease. The tooth may have recession, a swelling, localised inflammation of the gingival tissues or a discharging sinus. Evidence of parafunction may be observed during the clinical examination in the form of wear facets, or there may be abnormal mobility present warranting further investigation.

Part of the clinical examination will include an assessment of the offending tooth and the remaining structure in order to determine restorability. This may only be possible in some cases following the removal of an existing restoration and any associated caries. There is little benefit in considering periodontal and/or endodontic treatment if the tooth is damaged beyond repair. There are multiple indices available which can be used to determine a tooth's restorability. The authors and our colleagues utilise the Tooth Restorability Index (TRI) and the Dental Practicality Index (DPI), which scrutinise the amount of coronal dentine in order to determine how effectively the remaining tooth structure can support a direct/indirect restoration $(6,7)$.

\section{- Clinical Investigations}

- Radiographs are indicated in order to help confirm the diagnosis of a perio-endo lesion. A periapical is the radiograph of choice and is indicated where a recent one is unavailable. The radiograph will show areas of radiolucency which seem to originate from the interdental/interradicular area and from a distinct apical area. The area of radiolucency is evident on the lateral root surface and extends to the apical region. In the progressed state or where lateral canals are present, the furcation area may also be involved. Be wary of the 'J-shaped' radiolucent lesion (see Figure 2 ) as it is usually indicative of the presence of a root fracture, though further assessments are needed to diagnose it as such.

- Pulp Testing is routinely done by clinicians to determine whether the tooth remains innervated or not. The standard tests of ethyl-chloride, electrical pulp testing (EPT) and hot GP can be used quite easily chairside but may not always be appropriate for 
some teeth. Alternative temperature testing can be utilised where concerns arise. The author's endodontic colleague prefers the use of endo-frost as a cold test due to its suitability to test crowned teeth; and the use of a warm water bath where the tooth is isolated using a rubber dam and bathed in warm water to see if it elicits a response to heat. A negative vitality test in most cases will indicate a tooth requiring endodontic treatment or extraction, but the accuracy of individual tests means they cannot be relied upon as the sole indicators of tooth vitality.

- Detailed Periodontal Charting is essential for any assessment of periodontal disease. The charting should include a record of pocket depth, recession, attachment loss, bleeding/suppuration, furcation and mobility grading. The importance of plaque scores cannot be stressed enough. They are a vital aspect of managing disease and provide a record of monitoring on the clinician's behalf when faced with an uncompliant patient. For a patient with an existing periodontal diagnosis, comparisons can be made with previous charts to note disease progression or stability. If this is the first instance of this issue arising, a baseline chart is essential in order to monitor the success of future treatment.

- Occlusal testing is often an overlooked investigation but can help narrow the diagnosis and prevent irreversible damage to the tooth. Part of the history taking process should include questions pertaining to parafunctional habits and symptoms experienced during mastication or occluding. An occlusal assessment is routinely performed as part of a dental examination and includes recording movements, guidance, interferences and the presence of fremitus (8). A more detailed occlusal assessment and further investigations would be indicated where abnormalities present, or a traumatic element is suspected (9).

Using a tooth sleuth over individual cusps can help to determine whether a cracked cusp is present. Where a patient has had a restoration placed, marking the occlusal surfaces using articulating paper can help identify any high spots which can easily be adjusted chairside (10). Where an amalgam restoration is in place, the observant clinician may notice areas which appear to shine which can help identify discrepancies in occlusal loading.

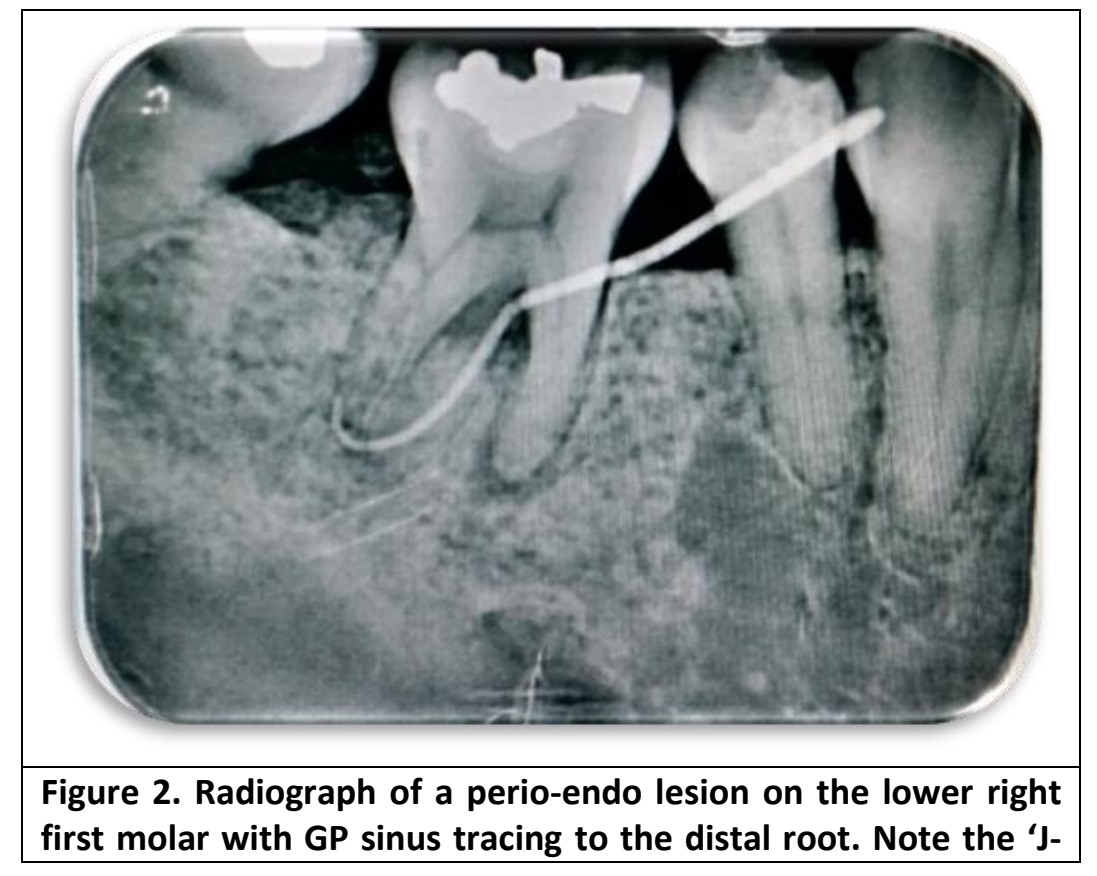


shaped' radiolucency on the mesial root and the radiolucent lesion in the area of the furcation. Image provided by Dr Shalini Kanagasingam.

\section{How does it feature in the $\mathbf{2 0 1 7}$ World Workshop Classification of Periodontal and Peri-Implant Diseases and Conditions?}

The 2017 World Workshop Classification of Periodontal and Peri-Implant Diseases and Conditions factors in the perio-endo lesion. Where a combined lesion presents, it falls under the category of 'Other Conditions Affecting the Periodontium' and can be put down as an Endodontic-Periodontal Lesion (11). The patient may have already been diagnosed with periodontitis and be undergoing treatment, monitoring or maintenance for this. The discovery of an endodontic component requires an adaptation to any ongoing treatment plan but does not justify putting all periodontal treatment on hold indefinitely where other sites of periodontitis exist.

\section{Management/Treatment}

The pathological origins of which came first are relevant in the management of disease where a primary endodontic or primary periodontal lesion exists. Where there is a primary endodontic lesion draining through the gingival crevice, successful endodontic treatment alone may lead to resolution of a narrow, isolated site. However, if there are any clinical and radiographic features of periodontal disease then both diseases must be treated, or their respective processes will continue. The management of this remains relatively unchanged and requires root canal treatment to be completed first, followed by the periodontal treatment (12).

Perio-endo lesions can present with some clinical challenges for any dentist. It is not uncommon to see increased pulpal calcification which can make endodontic treatment more complicated, particularly for a clinician who lacks the appropriate experience or access to the correct armamentarium (13). It is important to remember that any compromises in the endodontic treatment process will have a knock-on effect on the periodontal health and will prevent resolution of the lesion.

Some clinicians prefer to allow a period of healing following root canal treatment in order to determine whether endodontic treatment has been successful. This approach is acceptable, but should be taken with caution to ensure the periodontal condition is not left untreated for too long. Ideally initial non-surgical periodontal therapy should take place following completion of the endodontic treatment. The success of both treatment modalities can be reviewed at subsequent review appointments. A treatment flowchart can be seen in Figure 3.

Where the endodontic and/or periodontal aspects of treatment appear relatively straightforward, it would be appropriate to treat in primary care provided the general practitioner feels competent to do so. The clinician should be mindful about possible complications which may present and inform the patient of these before the start of treatment. There may be multiple factors which influence a patient's decision on whether to have treatment, what that treatment should be and who should provide it. It is the dentist's responsibility to ensure these options have been discussed during the decision-making process and to respect the patient's final decision. The decision tree in Figure 4 can be referred to if confusion persists on who should treat the patient.

There may be signs present on the radiographs or other clinical investigations which already indicate some case complexity e.g. calcifications, complex root anatomy, the presence of advanced disease. In these cases, it would be appropriate to refer to a specialist for a second opinion or treatment. In 
primary care a patient should be given the option of a specialist referral even when the case appears relatively simple in order to ensure the patient has been fully informed when deciding on care. Due to the common aspect of further training undertaken by general practitioners, the nature of primary care is changing; and patients now routinely have the option of being referred internally within the practice for specialist treatment instead of travelling to other locations or facing long waiting lists for consultations. The final decision on who ultimately undertakes treatment usually rests with one person, the patient.

When a patient is referred for specialist treatment of a combined lesion, it is likely to involve both an endodontist and periodontist. It is important that all clinicians who are involved with the treatment and long-term maintenance of the patient are all aware of the treatment plan, with a clear understanding of when treatment will take place and the aspect of treatment each clinician is responsible for. A sound treatment plan can fail when there is a breakdown in communication which can often be confusing or frustrating for the patient. The presence of a perio-endo lesion provides a great opportunity for specialists to work with each other in a multidisciplinary format and can help strengthen the team dynamic within a practice.

\section{A Novel Approach}

Varughese et al, (2015) proposed a surgical approach for the treatment of the perio-endo lesion involving root resection and regenerative therapy (14). Their case report features a perio-endo lesion on an upper first molar with significant bone loss on the disto-buccal root. Periodontal treatment was undertaken initially utilising systemic antibiotics, but no rationale was given as to why they were prescribed or why the endodontic treatment was not undertaken first. Endodontic treatment was subsequently undertaken using a conventional approach, with the disto-buccal tooth being resected three months after this was completed. Following resection, regenerative surgery was undertaken using platelet rich fibrin with bone grafting and a guided tissue regeneration membrane. Positive results were noted following an annual review.

However, this approach was utilised on a single patient and may not be suitable for every patient. It should be noted that the endodontic treatment was not done using a new approach and there is little mention of the endodontic outcomes following review. It is the authors' belief that any antimicrobial use should be carefully considered due to the very real concerns pertaining to antibiotic resistance (15). Any deviations from the accepted evidence base, in this case undertaking periodontal therapy before addressing the endodontic issues, needs to have a good justification which is discussed with the patient and documented clearly in the patient's records. 
HISTORY

Known endodontic lesion

Known periodontal disease

+/-pain

High caries/perio risk

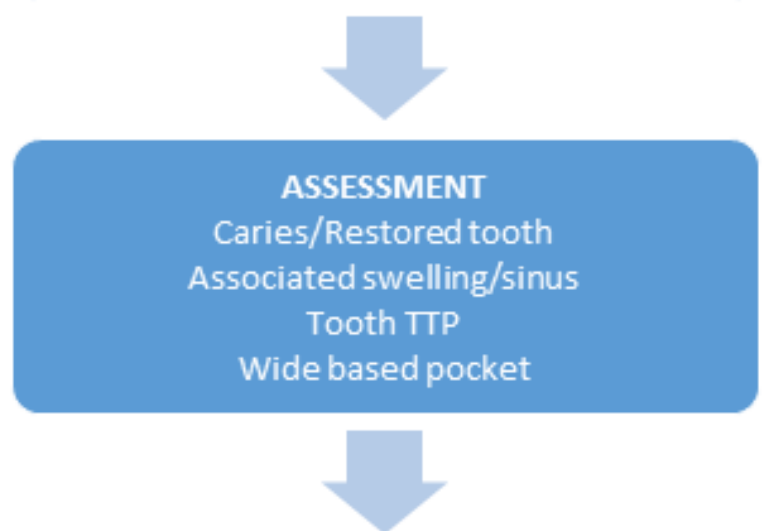

INVESTIGATIONS

Coalescing radiolucencies

-ve to vitality testing

Pocketing +/-suppuration

Tooth Mobile

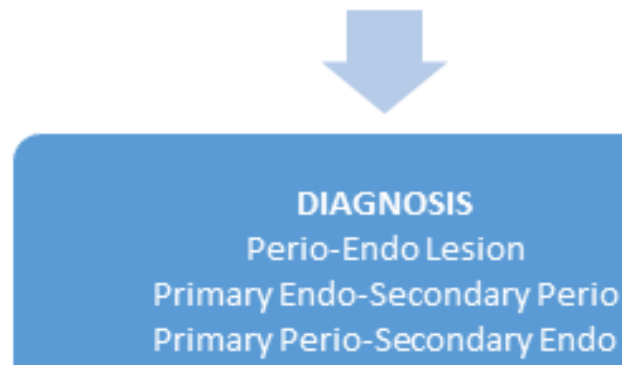

Primary Perio-Secondary Endo

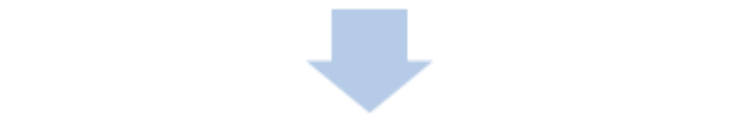

\section{TREATMENT}

(1) Endodontic treatment

(2) Periodontal treatment

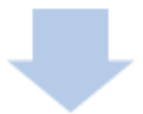

\section{REVIEW}

Symptoms suggesting treatment failure

Periodontal review 3 months

Radiographic review of RCT 1 year post op

Figure 3. A treatment flowchart for the Perio-Endo Lesion 
PERIO-ENDO LESION DIAGNOSED
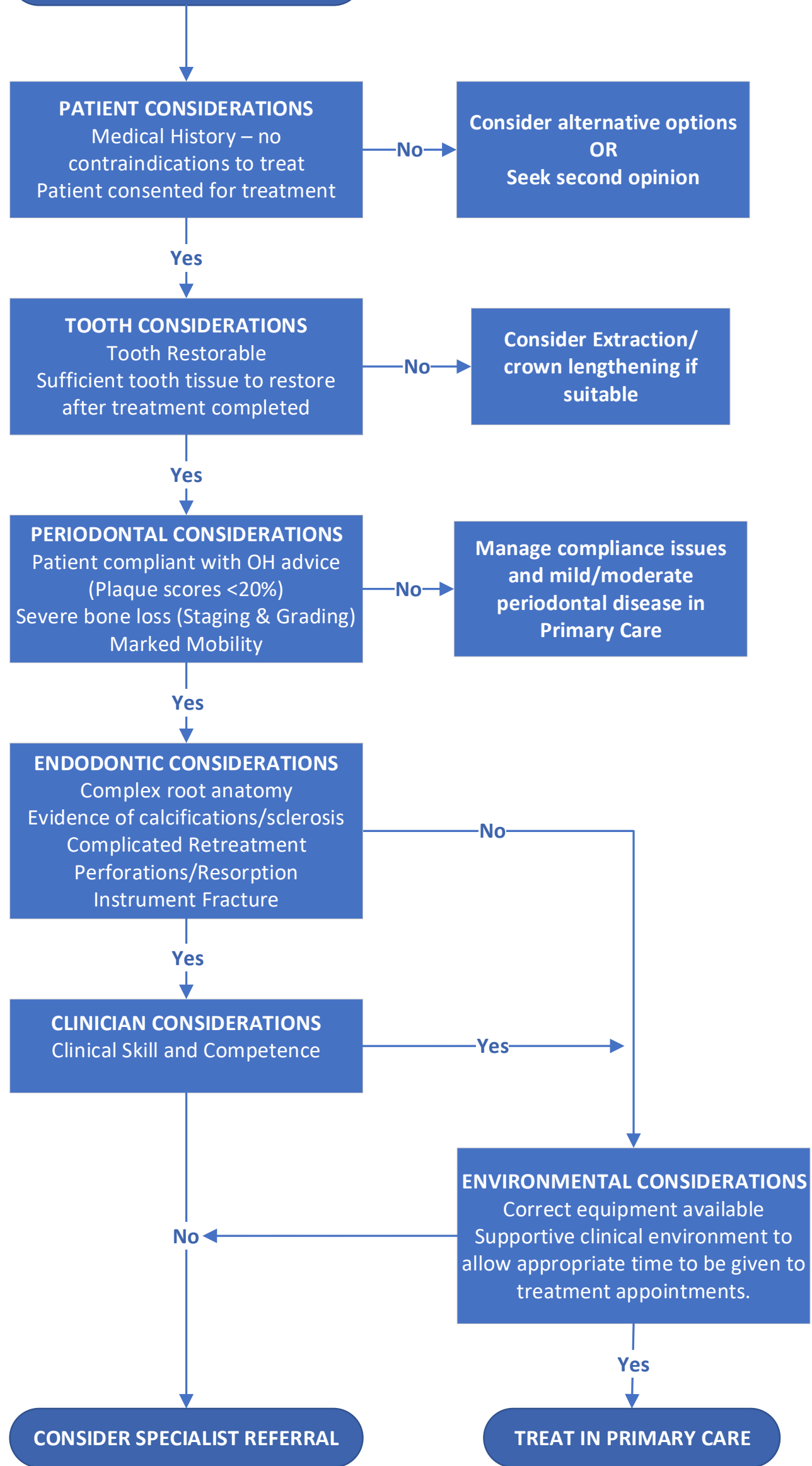


\section{Figure 4. A decision tree to determine suitability for referral to specialist dentists based on individual clinical features}

\section{Factors Affecting Success}

The completion of endodontic and periodontal treatment does not guarantee success and multiple factors can influence the prognosis of treatment. The main factors affecting success are as follows:

- The extent of disease. Where disease is severe and there has been considerable tissue loss, the chances of success are reduced, especially where trauma or iatrogenic complications are identified (16).

- Size of lesion. The bigger the lesion, the less likely that it will resolve completely. Success rates can be as high as $82.8 \%$ (for primary endodontic treatment) where there is no radiographic apical lesion; with the odds of success decreasing by $49 \%$ where radiographic pathology is evident (17). Where apical lesions are quite large, the existence of other pathologies should be kept in mind.

- Severity of mobility. If there has been extensive bone loss, the tooth is likely to present with considerable mobility. In such cases the prognosis of success is reduced. Extraction may be indicated for the single-rooted tooth and more complex treatment like hemi-section or root resection could be considered where the pattern of bone loss is not consistent on all roots.

- The patient's ability to comply with oral care advice to maintain periodontal health following treatment. All forms of periodontal treatment rely on good plaque control, which remains the responsibility of the patient. This should be made clear to the patient when plaque induced periodontal disease has been diagnosed and appropriately tailored hygiene advice given, reviewed and reinforced at subsequent visits.

- Clinical skill - All dentists are not blessed with the same level of skill, and a good clinician is able to recognise this and discuss the available options with their patient, including that of specialist referral. Where case complexity is evident which exceeds the clinician's competence, a referral should be considered following honest discussion with the patient.

- Environmental Factors - This refers to the practice environment in which treatment is intended to take place. Though not widely discussed, practices remain where endodontic treatment is undertaken without rubber dam, with a substandard irrigant or without the correct tools available to ensure a high standard of care. Patients who have non-surgical periodontal treatment undertaken without anaesthetic or even baseline charting remain plentiful. In busy target-driven environments, time remains a valuable commodity and complex conditions like the combined lesion are not always given the time they need to treat them appropriately. Where this is the case, referral should be considered at the outset to save the patient unnecessary time, cost and suffering.

These factors may work independently or in combination to affect whether a perio-endo lesion resolves and should be made clear to the patient during the decision-making process and as the clinical picture changes during the review process.

\section{Conclusion}

When a patient presents for an appointment it is imperative for the clinician to perform a thorough assessment of their condition, whether they present with symptoms or not. It can be easy to misdiagnose a patient who presents with symptoms as having a condition presenting from a single aetiological cause. We are often taught when diagnosing a patient in pain that the cause will originate from either the gum or the tooth - it is rarely both or neither. But there will be those small pockets of 
patients who fall into this rare category and it is a clinician's duty to ensure a comprehensive evaluation has been performed in order to diagnose and treat appropriately. The possibility of a perioendo lesion should be considered where the clinical picture suggests multiple sources of pathology.

When a diagnosis of a perio-endo lesion is made, appropriate management is crucial to success, with case selection being integral to managing in a primary care setting. This may result in part/all the clinical treatment being shared with another clinician. Where multiple clinicians or specialists are involved with the treatment process, clear communication is essential between all parties to manage the patient's condition. It is important to ensure the patient is appropriately informed about what to expect at each stage and understands both the short and long-term maintenance plans for their individual case. In the case of a combined lesion, or where periodontal disease exists in a patient with an endodontic lesion, both specialties must be addressed with the endodontic condition being treated first, followed by the periodontal disease.

\section{REFERENCES}

(1) Simon JH, Glick DH, Frank AL. The relationship of endodontic-periodontal lesions. Journal of Periodontology 1972; 43: 202-208.

(2) Belk CE, Gutmann JL. Perspectives, controversies, and directives on pulpal-periodontal relationship. Journal Canadian Dental Association 1990; 56(11):1013-1017.

(3) The Good Practitioners Guide to Periodontology, British Society of Periodontology, [online] Available from: https://www.bsperio.org.uk/publications/good practitioners guide 2016.pdf?v=3 Accessed $30^{\text {th }}$ April 2020.

(4) Odell EW, Cawson RA. Cawson's essentials of oral pathology and oral medicine. Ninth edition / E.W. Odell. Amsterdam: Elsevier; 2017.

(5) Hargreaves KM, Berman LH, Rotstein I. Cohen's pathways of the pulp. 11th edition. Saint Louis, Missouri: Elsevier; 2016.

(6) McDonald A, Setchell D. Developing a tooth restorability index. Dental Update 2005; 32: 343344.

(7) Dawood A, Patel S. The Dental Practicality Index - assessing the restorability of teeth. British Dental Journal 2017; 222(10):755-758.

(8) Faculty of General Dental Practice (UK), Clinical Examination and Record-Keeping Good practice. 3rd edition. London: Faculty of General Dental Practice (UK); 2013.

(9) McCullock AJ. Making Occlusion Work: I. Terminology, Occlusal Assessment and Recording. Dental Update 2003; 30:150-157.

(10)Davies SJ, Gray RMJ. The examination and recording of the occlusion: why and how. British Dental Journal 2001; 191:291-302.

(11)Papapanou PN et al. Periodontitis: Consensus report of workgroup 2 of the 2017 World Workshop on the Classification of Periodontal and Peri-Implant Diseases and Conditions. Journal of Periodontology 2018; 89(1):S172-S182.

(12)Schmidt JC, Walter C, Amato M, Weiger R. Treatment of periodontal-endodontic lesions - a systematic review. Journal of Clinical Periodontology 2014; 41: 779-790. 
(13)Gautam S et al. Pulpal changes associated with advanced periodontal disease: A histopathological study. Journal of Oral and Maxillofacial Pathology 2017; 21(1):58-63.

(14)Varughese V, Mahendra J, Thomas AR, Ambalavanan N. Resection and Regeneration - A Novel Approach in Treating a Perio-endo Lesion. Journal of Clinical \& Diagnostic Research 2015; 9(3):ZD08-ZD10.

(15)Antibiotic Resistance: Key Facts, World Health Organisation [online] Available from: https://www.who.int/en/news-room/fact-sheets/detail/antibiotic-resistance Accessed 20th July 2020.

(16)Herrera D, Retamal-Valdes B, Alonso B, Feres M. Acute periodontal lesions (periodontal abscesses and necrotizing periodontal diseases) and endo-periodontal lesions. Journal of Clinical Periodontology 2018; 45(20): S78- S94.

(17)Ng YL, Mann V, Gulabivala K. A prospective study of the factors affecting outcomes of nonsurgical root canal treatment: part 1: periapical health. International Endodontic Journal 2011; 44(7):583-609.

(18)Sjögren $U$ et al. Factors Affecting the Long-term Results of Endodontic Treatment. Journal of Endodontics 1990; 16(10): 498-504. 